\title{
Study of Imatinib Cardiotoxicity In Adult Male Rabbits
}

\author{
Nermeen A M Hassan ${ }^{1}, *$ Mohamed M. Yousef ${ }^{2}$ \\ ${ }^{1}$ (Forensic Medicine and Clinical Toxicology Department/ Benha University, Egypt) \\ ${ }^{2}$ (Histology and Cell Biology Department/ Benha University, Egypt)
}

\begin{abstract}
Imatinib (Imb) mesylate is fully approved for the treatment of patients with chronic myeloid leukaemia (CML) in chronic phase after failure of interferon- therapy in blast crisis and in accelerated phase. Cardiotoxicity is an important consideration in the evaluation of cancer chemotherapy, because chemotherapyinduced myocardial damage might be irreversible and lethal. The aim of this work is to evaluate the cardiotoxicity of Imatinib mesylate following repeated administration of different doses and periods in adult male rabbits. fifty four adult male rabbits were utilized and divided equally into 3 groups: control group (group I), low dose Imb group (group II); received orally Imatinib mesylate (50 $\mathrm{mg} / \mathrm{kg} /$ day) for 4 weeks and high dose Imb group (group III); received orally Imatinib mesylate (100 mg/kg/day) for 4 weeks. Cardiotoxicity was evaluated by electrocardiograph (ECG), biochemical and histopathological examination. Specimens and samples were taken 2 and 4 weeks from the start of the experiment and 2 weeks after drug withdrawal. ECG revealed left ventricular contractile dysfunction and mild diastolic dysfunction. Imb treated groups resulted in significant increases $(\leq 0.001)$ in serum creatine kinase isoenzyme $(C K-M B)$, cardiac troponin $T(c T n c T)$, lactate dehydrogenase $(\mathrm{LDH})$ and aspartate aminotransferase (AST) activity levels. Cardiac tissue of rats treated with imatinib showed significantly increased cardiac MDA production level and significant decreased ( $\leq$ 0.001) glutathione peroxidase (GPx) activity level and Total nitrate/nitrite (Nox) content. Those changes were proportional increase with increase dose and time of Imb and irreversible after stoppage of drugs. Imatinib mesylate have significant cardiotoxicity that alarming oncologists to avoid medication errors with Imb either large dose or for long periods administration that may have resulted in fatalities.
\end{abstract}

Key Words: Imatinib, cardiotoxicity, electrocardiography, cardiac troponin

\section{Introduction}

Imatinib (Imb), an example of a molecular-targeted drug, has revolutionized treatment of chronic myeloid leukaemia (CML), and is now recommended as standard treatment for the accelerated and chronicphase disease [1], as well as for the management of advanced gastrointestinal stromal tumors [2].

Authors [3] reported CML have a gene mutation called the Philadelphia chromosome. Every cell in the body contains DNA that determines how the cell looks and acts. DNA is contained inside chromosomes. Chromosomal changes in CML, part of the DNA from one chromosome moves to another chromosome. This change is called the" Philadelphia chromosome." It results in the bone marrow making an enzyme, called tyrosine kinase, that causes too many stem cells to become white blood cells (granulocytes or blasts) (Fig. A) [3].

The principal target of Imb is BCR-ABL, a fusion protein made up of part of the breakpoint cluster region (BCR) protein and part of the tyrosine kinase Abelson murine leukemia (ABL). Imb directly binds to the tyrosine kinase domain of BCR-ABL and inhibits its oncogenic activity in CML. By inhibiting BCR-ABL kinase activity, Imb effectively blocks the proliferation signal within leukemic progenitor cells and induces apoptotic cell death in cells expressing this activated kinase [4]. It is also effective against other tyrosine kinases, including ABL, stem cell factor receptor C-kit, and the platelet-derived growth factor receptor [5].

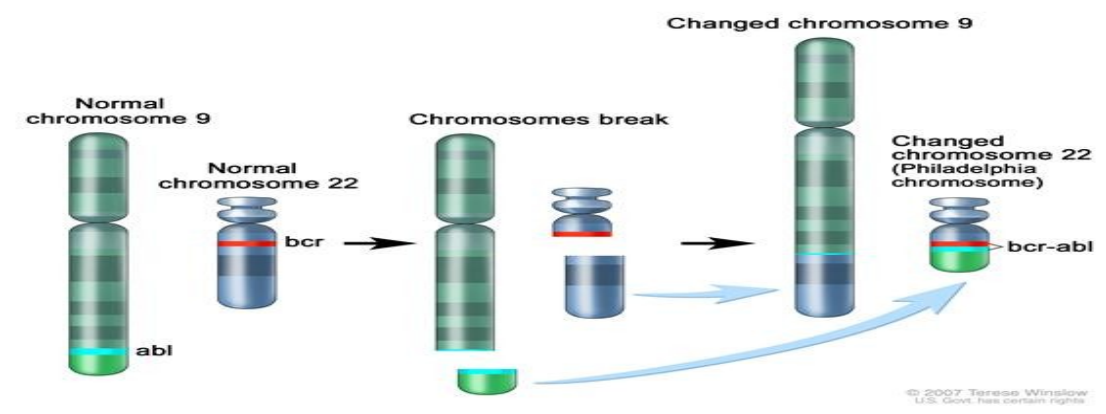


Fig. A Philadelphia chromosome. A piece of chromosome 9 and a piece of chromosome 22 break off and trade places. The BCR-ABL gene is formed on chromosome 22 where the piece of chromosome 9 attaches. The changed chromosome 22 is called the Philadelphia chromosome [3].

$\mathrm{Imb}$ is generally well tolerated and the most frequently reported adverse effects, occurring in less than $10 \%$ of patients [6], [7]. The retrospective reports, denying the existence of significant cardiotoxicity related to $\operatorname{Imb}$, were considered insufficient to assure that adverse cardiac effects are not a major issue in this therapy [8]. There are controversial data on the role of $\operatorname{Imb}$, on cardiac function. Considering the importance of this controversy and the absence of reliable data so there is a need for studies to evaluate how frequently cardiotoxicity develops in patients receiving $\mathrm{Imb}$, taking into account dose administration and period of the drug.

\section{Aim of the work}

This study was conducted to evaluate the cardiotoxicity of Imatinib following repeated administration of different doses and periods in adult male rabbits.

\section{Material and Methods}

In this study, 54 adult male rabbits were utilized with an average weight 2000-2600 grams/each. Rabbits were housed in special cages and were maintained on standard laboratory conditions, fed ad libitum and free access to tap water. Considering ethical considerations of studies in experimental animals.

\section{Drug:}

Imatinib doses:

Imatinib mesylate (Gleevec) capsules $(100 \mathrm{mg}$ ) were obtained from Novartis Pharma Egypt and the powder was dissolved in distilled water $(10 \mathrm{mg} / \mathrm{mL})$ and given orally (orogastric tube).

$\mathrm{Imb}$ doses selected were intended to be in the range of those used in clinical treatment regimens $(400-800 \mathrm{mg} / \mathrm{d}$ or $228-456 \mathrm{mg} / \mathrm{m} 2$ based on a weight of $70 \mathrm{~kg}$ ). The highest dose of $I m b$ used was $100 \mathrm{mg} / \mathrm{kg}$, which is equivalent to590 $\mathrm{mg} / \mathrm{m} 2$ [9].

Two doses of Imatinib mesylate were calculated and given; the lowest is $50 \mathrm{mg} / \mathrm{kg} / \mathrm{day}$ and the highest is $100 \mathrm{mg} / \mathrm{kg}$ / day for rabbits $\operatorname{Imb}$ doses selected were intended to be in the range of those used in clinical treatment regimens $(400-800 \mathrm{mg} / \mathrm{d})$. The doses for rabbits were calculated according to Paget's formula, Paget and Barnes $[10]$.

\section{Animals:}

Rabbits were divided equally into three groups; $n=18$ each:

Group I (control group): received daily distilled water through orogastric tube.

Group II. (low dose Im group): received daily oral dose $(50 \mathrm{mg} / \mathrm{kg}$ ) of Imatinib mesylate for 4 weeks.

Group III (high dose Im group) :received daily oral dose $(100 \mathrm{mg} / \mathrm{kg})$ of Imatinib mesylate for 4 weeks. Methods:

\section{Echocardiography (ECG):}

Echocardiography was performed using MyLab 26 (Esaote, Italy) with a $13 \mathrm{MHz}$ linear array transducer. Resting scans were acquired in standard apical 4-chamber and apical 2-chamber. LV volumes were obtained by biplane echocardiography, and LVEF was derived from a modified Simpson's formula. Each rabbit was examined at baseline, $2 \& 4 \mathrm{wks}$ after treatment initialization, and 2 weeks after termination of treatment (washout) under light anesthesia (i.p. ketamine $\mathrm{HCl}$ and xylazine 75 and $3.5 \mathrm{mg} / \mathrm{kg}$ body weight, respectively,) [11].

\section{Biochemical evaluation: \\ Serum and tissue sampling \\ 2.1 Sample Analysis:}

Rabbits were anaesthetized with ether and $5 \mathrm{ml}$ of blood samples were taken by catheter of carotid artery were taken at 2,4 and 6 weeks (wash-out). Serum was separated by centrifugation at 3000 r.p.m. $/ 15$ minutes and used to determine Terminal serum levels of cardiac troponin T (cTnc T), creatine phosphokinase (CPK-MB), lactate dehydrogenase (LDH) and Asparate aminotransferase (AST).

1.1.1 Terminal serum levels of cardiac troponin $\mathbf{T}$ (cTnc $\mathbf{T}$ ): Assays for cTnT was performed with sensitive second- and third-generation assays with reagents provided by Roche Diagnostics (Indianapolis, IN) and DADE (Newark, DE) [12],[13]. The measurement of serum concentrations of cardiac troponin T (TnT) is a simple, useful method to detect myocyte injury that may be repeated multiple times to follow patients without inter observer variability [14]. 


\subsubsection{Serum creatine kinase-MB isoenzyme (CK-MB),}

Immunoassays for CK-MB mass was utilized according Mair et al. [15].

\subsection{3 lactate dehydrogenase (LDH):}

Serum LDH activity was determined with an LDH Cytotoxicity Detection Kit (Roche Molecular Biochemicals, Rotkreuz, Switzerland) according to [16].

2.1.4 Asparate aminotransferase (AST):

Serum AST activity was assayed by the method of Mohur and Cook [17].

\subsection{Preparation of tissue homogenates}

Specimens from heart tissues were separated into two parts. The tissues were homogenized and the centrifuged homogenates were stored at $-26^{\circ} \mathrm{C}$ until they were analyzed.

2.2.1 Cardiac Malondialdehyde (MDA): is the breakdown product of lipid peroxidation and was analyzed according to the method by Valenzuela [18].

2.2.2 Cardiac glutathione peroxidase (GPx) activity was determined by Paglia \& Valentine [19]

2.2.3 Total nitrate/nitrite (NOx) were determined according to Miranda et al[20] methods.

\subsection{Light microscope examination (EM):}

\section{Histopathology studies:}

Hearts was dissected out. Vascular perfusion fixation through the left ventricle with $1 \%$ glutaraldhyde was performed. Left ventricular heart specimens were taken 2, 4 and 6 weeks (wash-out) and paraffin sections were prepared for LM examination):

3.1.1 Hematoxylin and Eosin (H\&E) [21];

3.1.2 Masson's trichrome [22];

3.1.3 Immunohistochemical detection of caspase-3. The mean area \% for brown cytoplasmic staining (caspase-3 expression) was quantified in 10 images for the $2^{\text {nd }}, 4^{\text {th }}$ and $6^{\text {th }}$ weeks sections of each group using Image-Pro Plus program version 6.0. (Media Cybernetics, Inc. Georgia Avenue, USA).

\subsection{Electron microscopic (EM):}

For EM preparation, heart specimens were processed and ultrathin sections prepared [23] in Tanta EM unit.

\section{Statistical analysis:}

The collected data were tabulated and analyzed using SPSS 16 soft ware. Student " $\mathrm{t}$ " test was used to compare 2 independent means. Difference were considered to be statistically significant if $\mathrm{P}<0.05$ [24].

1. Echocardiographic (ECG) analysis:

\section{Results:}

ECG of rabbits treated with low dose of Imb (group II) showed the abnormal relaxation pattern (mild diastolic dysfunction), a reduced velocity of early filling ( $\mathrm{E}$ wave), an increase in the velocity associated with atrial contraction (A wave), and a ratio of E to A that is lower than normal. ECG of rabbits treated with Imb in high dose (group III) showed left ventricular pressure-volume loops in systolic and diastolic dysfunction (Fig. I \&II).

\section{Biochemical analysis of cardiac markers:}

- $\quad$ Serum isoenzymes:

- $\quad$ There was significantly increase cTncT concentrations in rabbits treated with $\operatorname{Imb}$ with persistently increased (group III).

- $\quad$ Rabbits treated with $\operatorname{Imb}$ resulted in significant increases in the rate of change of serum CK-MB activity, LDH and AST levels compared with control group $(\mathrm{P}<0.01)$.

- Cardiac tissue MDA, GPX and Nox:

- $\quad$ Treatment of rabbits with $I m b$, revealed significant increase $(\mathrm{P}<0.01)$ in the cardiac's MDA production compared with the control group.

There were significant reduction $(\mathrm{P}<0.01)$ in cardiac GPx activity and total NOx content compared with the control group $(\mathrm{P}<0.01)$ (Table $1,2 \& 3)$.

\section{Histopathological changes:}

3.1. Light microscope (LM):

\subsubsection{Hematoxylin and Eosin:}




\section{Low dose of $\operatorname{Imb}$ (group II):}

$\begin{array}{lcl}- & \text { In } 2^{\text {nd }} \text { week: it showed normal cardiac myocytes compared with control group (Fig. 1). } \\ - & \text { In } 4^{\text {th }} \text { week: mild cytoplasmic vacuolization (Fig. } 2 \text { ) that became normal in the } 6^{\text {th }} \text { week sections (wash- }\end{array}$ out).

\section{High dose Imb group (group III):} (Fig. 3).

- In $4^{\text {th }}$ week: it became sever with widened intercellular space in the $4^{\text {th }}$ week sections (Fig. 4).

- The $6^{\text {th }}$ week sections (wash-out) showed moderate cytoplasmic vacuolization and pyknosis of some cardiac myocytes (Fig. 5).

3.1.2. Masson's trichrome study: In low dose $\operatorname{Imb}$ group, it showed no increase in collagen fibers accumulation while in high dose, it showed slight increase in collagen fibers accumulation between cardiac myocytes in the $4^{\text {th }}$ week sections as compared with control (Fig. 6-7).

\subsubsection{Immunohistochemical study:}

Positive immuno - histochemical staining of caspase- 3 demonstrated as brown cytoplasmic staining (index for the degree of nuclear apoptosis) which was negative reaction in control group (Fig. 8).

In low dose Imb group: caspase-3 was mildly expressed in cytoplasm of cardiac myocytes in the $4^{\text {th }}$ week sections (Fig. 9) and became negative in $6^{\text {th }}$ week sections.

In high dose Imb group: caspase- 3 was moderately expressed in cytoplasm of cardiac myocytes in the $2^{\text {nd }}$ week sections (Fig. 10) that became highly expressed in the $4^{\text {th }}$ week sections (Fig. 11). It showed moderate cytoplasmic expression in cardiac myocytes in the $6^{\text {th }}$ week sections (Fig. 12) (Table, 4 ).

\subsection{Electron microscope (EM) study:}

In low dose Imb group: it showed partial myofibrils disorganization, mild vacuolization and slight mitochondrial swelling in the $4^{\text {th }}$ week sections (Fig. 15) while in the $6^{\text {th }}$ week sections (wash-out), it showed normal cardiac myocytes compared with control group (Fig. 13-14).

\section{In high dose Imb group:}

- In the $2^{\text {nd }}$ week: it showed myofibrils disorganization, moderate cytoplasmic vacuolization and mitochondrial swelling with disruption of the cristae (Fig. 16) that became marked in the $4^{\text {th }}$ week sections with extensive myofibrils disorganization, vacuolization, atrophic mitochondria with disruption of the crista and sarcoplasmic reticulum forming a membrane whorls immediately adjacent to mitochondria (Fig. 17).

- In the $6^{\text {th }}$ week (withdrawal sample): it showed partial myofibrils disorganization, moderate cytoplasmic vacuolization and mitochondrial swelling with disruption of the cristae (Fig. 18).

Table 1 Biochemical Parameters Of Different Cardiac Markers In Rabbits Treated With Imb After 2

\begin{tabular}{|c|c|c|c|c|c|c|c|}
\hline & CTnc T(ng/ml) & $\begin{array}{l}\text { CK- } \\
\text { MB(ng/ml) }\end{array}$ & $\begin{array}{l}\operatorname{AST}(\mathbf{I U} / \\
\text { L) }\end{array}$ & LDH(IU/L) & $\begin{array}{l}\text { MDA(nmol/g } \\
\text { wet tissue) }\end{array}$ & $\begin{array}{l}\mathrm{Gpx}(\mu \mathrm{mo} / \mathrm{g} \\
\text { wet tissue })\end{array}$ & $\begin{array}{l}\text { Nox }(\mu \mathrm{mol} / \\
\text { g wet } \\
\text { tissue })\end{array}$ \\
\hline Gr. I(n=6) & $0.013 \pm 0.01$ & $5.1 \pm 2.1$ & $33 \pm 1.54$ & $134.7 \pm 5.23$ & $62 \pm 2.43$ & $14.45 \pm 1.3$ & $48 \pm 1.55$ \\
\hline Gr. II(n=6) & $1.6 \pm 1.1$ & $8.6 \pm 2.26$ & $53 \pm 3.11$ & $287.1 \pm 23.12$ & $96 \pm 8.31$ & $12.38 \pm 1.11$ & $34.5 \pm 3.90$ \\
\hline $\begin{array}{l}t \text { test } \\
p\end{array}$ & $\begin{array}{l}3.23 \\
0.009 *\end{array}$ & $\begin{array}{l}2.78 \\
0.019 *\end{array}$ & $\begin{array}{l}14.12 \\
<0.001 *\end{array}$ & $\begin{array}{l}15.74 \\
<0.001^{*}\end{array}$ & $\begin{array}{l}9.62 \\
<0.001 *\end{array}$ & $\begin{array}{l}2.98 \\
0.013 *\end{array}$ & $\begin{array}{l}7.88 \\
<0.001 *\end{array}$ \\
\hline Gr. III(n=6) & $3.4 \pm 1.6$ & $12.4 \pm 3.4$ & $71 \pm 4.12$ & $351.3 \pm 28.17$ & $112 \pm 9.5$ & $10.18 \pm 2.07$ & $26 \pm 4.10$ \\
\hline $\begin{array}{l}\text { t test } \\
p\end{array}$ & $\begin{array}{l}5.18 \\
<0.001 *\end{array}$ & $\begin{array}{l}4.47 \\
0.001 *\end{array}$ & $\begin{array}{l}21.20 \\
<0.001 *\end{array}$ & $\begin{array}{l}18.51 \\
<0.001 *\end{array}$ & $\begin{array}{l}12.50 \\
<0.001 *\end{array}$ & $\begin{array}{l}4.28 \\
0.0016 *\end{array}$ & $\begin{array}{l}12.30 \\
<0.001 *\end{array}$ \\
\hline Gr. II(n=6) & $1.6 \pm 1.1$ & $7.6 \pm 2.26$ & $53 \pm 3.11$ & $287.1 \pm 23.12$ & $96 \pm 8.31$ & $12.38 \pm 1.11$ & $34.5 \pm 3.90$ \\
\hline Gr. III (n=6) & $3.4 \pm 1.6$ & $12.4 \pm 3.4$ & $71 \pm 4.12$ & $351.3 \pm 28.17$ & $112 \pm 9.5$ & $10.18 \pm 2.07$ & $26 \pm 4.10$ \\
\hline $\begin{array}{l}\text { t test } \\
p\end{array}$ & $\begin{array}{l}2.27 \\
0.046^{*}\end{array}$ & $\begin{array}{l}2.28 \\
0.045^{*}\end{array}$ & $\begin{array}{l}8.54 \\
<0.001 *\end{array}$ & $\begin{array}{l}4.32 \\
0.001 *\end{array}$ & $\begin{array}{l}3.11 \\
0.01 *\end{array}$ & $\begin{array}{l}2.29 \\
0.045 *\end{array}$ & $\begin{array}{l}3.68 \\
0.004 *\end{array}$ \\
\hline
\end{tabular}

$* \mathrm{P}$ is considered statistically significant if $\leq 0.05$. 
Table 2 Serum Biochemical Parameters Of Different Cardiac Markers In Rabbits Treated With Imb After 4 Wks:(n=6)

\begin{tabular}{|c|c|c|c|c|c|c|c|}
\hline & $\begin{array}{l}\text { CTnc } \\
\text { T(ng/ml) }\end{array}$ & $\begin{array}{l}\text { CK- } \\
\mathrm{MB}(\mathrm{ng} / \mathrm{ml})\end{array}$ & $\operatorname{AST}(I U / L)$ & LDH(IU/L) & $\begin{array}{l}\text { MDA(nmol/g } \\
\text { wet tissue) }\end{array}$ & $\begin{array}{l}\text { Gpx( } \mu \mathrm{mo} / \mathrm{g} \\
\text { wet tissue })\end{array}$ & $\begin{array}{l}\mathrm{Nox}(\mu \mathrm{mol} / \mathrm{g} \\
\text { wet tissue) }\end{array}$ \\
\hline Gr. I(n=6) & $0.013 \pm 0.01$ & $5.1 \pm 2.1$ & $33 \pm 1.54$ & $134.7 \pm 5.23$ & $62 \pm 2.43$ & $14.45 \pm 1.3$ & $48 \pm 1.55$ \\
\hline Gr. II(n=6) & $3.6 \pm 1.4$ & $11.31 \pm 2.8$ & $144 \pm 13.52$ & $799.3 \pm 66.7$ & $123 \pm 10.4$ & $.5 \pm 1.610$ & $22 \pm 5.34$ \\
\hline $\begin{array}{l}t \text { test } \\
p\end{array}$ & $\begin{array}{l}6.27 \\
<0.001 *\end{array}$ & $\begin{array}{l}4.35 \\
0.001 *\end{array}$ & $\begin{array}{l}19.98 \\
<0.001 *\end{array}$ & $\begin{array}{l}24.3 \\
<0.001 *\end{array}$ & $\begin{array}{l}14.00 \\
<0.001 *\end{array}$ & $\begin{array}{l}16.5 \\
<0.001 *\end{array}$ & $\begin{array}{l}11.45 \\
<0.001 *\end{array}$ \\
\hline Gr. III $(n=6)$ & $5.76 \pm 1.7$ & $15.86 \pm 3.4$ & $176 \pm 13.6$ & $893.0 \pm 72.1$ & $154 \pm 11.8$ & $8.58 \pm 1.8$ & $13 \pm 4.7$ \\
\hline $\begin{array}{l}t \text { test } \\
p\end{array}$ & $\begin{array}{l}8.28 \\
<0.001 *\end{array}$ & $\begin{array}{l}6.6 \\
<0.001 *\end{array}$ & $\begin{array}{l}25.6 \\
<0.001 *\end{array}$ & $\begin{array}{l}25.7 \\
<0.001 *\end{array}$ & $\begin{array}{l}18.7 \\
<0.001 *\end{array}$ & $\begin{array}{l}6.47 \\
<0.001 *\end{array}$ & $\begin{array}{l}17.3 \\
<0.001 *\end{array}$ \\
\hline Gr. II(n=6) & $3.6 \pm 1.4$ & $11.31 \pm 2.8$ & $144 \pm 13.52$ & $799.3 \pm 66.7$ & $123 \pm 10.4$ & $0.5 \pm 1.61$ & $22 \pm 5.34$ \\
\hline Gr. III (n=6) & $5.76 \pm 1.7$ & $15.86 \pm 3.4$ & $176 \pm 13.6$ & $893.0 \pm 72.1$ & $154 \pm 11.8$ & $8.58 \pm 1.8$ & $13 \pm 4.7$ \\
\hline $\begin{array}{l}t \text { test } \\
p\end{array}$ & $\begin{array}{l}2.40 \\
0.037 *\end{array}$ & $\begin{array}{l}2.530 \\
0.029 *\end{array}$ & $\begin{array}{l}4.09 \\
0.002 *\end{array}$ & $\begin{array}{l}2.34 \\
0.04 *\end{array}$ & $\begin{array}{l}4.83 \\
<0.001 *\end{array}$ & $\begin{array}{l}8.2 \\
<0.001 *\end{array}$ & $\begin{array}{l}3.1 \\
0.011 *\end{array}$ \\
\hline
\end{tabular}

$* \mathrm{P}$ is considered statistically significant if $\leq 0.05$.

Table 3 Biochemical Parameters Of Different Cardiac Markers In Rabbits Treated With Imb After 6

Wks (Wash-Outl Samples For 2 Weeks):(n=6)

\begin{tabular}{|c|c|c|c|c|c|c|c|}
\hline & $\begin{array}{l}\text { CTnc } \\
\text { T(ng/ml) }\end{array}$ & $\begin{array}{l}\text { CK- } \\
\text { MB(ng/ml) }\end{array}$ & $\operatorname{AST}(\mathbf{I U} / \mathbf{L})$ & LDH(IU/L) & $\begin{array}{l}\text { MDA(nmol/g } \\
\text { wet tissue) }\end{array}$ & $\begin{array}{l}\mathrm{Gpx}(\mu \mathrm{mo} / \mathrm{g} \\
\text { wet tissue })\end{array}$ & $\begin{array}{l}\text { Nox }(\mu \mathrm{mol} / \mathrm{g} \\
\text { wet tissue })\end{array}$ \\
\hline Gr. $I(n=6)$ & $0.013 \pm 0.01$ & $5.1 \pm 2.1$ & $33 \pm 1.54$ & $134.7 \pm 5.23$ & $62 \pm 2.43$ & $14.45 \pm 1.3$ & $48 \pm 1.55$ \\
\hline Gr. II(n=6) & $2.3 \pm 1.03$ & $9.6 \pm 2.47$ & $135 \pm 12.87$ & $693 \pm 62.40$ & $116 \pm 9.76$ & $11.22 \pm 2.06$ & $24 \pm 5.26$ \\
\hline $\begin{array}{l}\text { t test } \\
p\end{array}$ & $\begin{array}{l}5.43 \\
<0.001 *\end{array}$ & $\begin{array}{l}3.4 \\
0.006 *\end{array}$ & $\begin{array}{l}19.3 \\
<0.001 *\end{array}$ & $\begin{array}{l}21.84 \\
<0.001 *\end{array}$ & $\begin{array}{l}13.20 \\
<0.001 *\end{array}$ & $\begin{array}{l}3.250 \\
0.008^{*}\end{array}$ & $\begin{array}{l}10.72 \\
<0.001 *\end{array}$ \\
\hline Gr. III(n=6) & $4.1 \pm 1.42$ & $13.26 \pm 2.76$ & $162 \pm 13.1$ & $835 \pm 73.20$ & $144 \pm 11.19$ & $9.20 \pm 2.00$ & $16 \pm 4.88$ \\
\hline $\begin{array}{l}\text { t test } \\
p\end{array}$ & $\begin{array}{l}7.05 \\
<0.001 *\end{array}$ & $\begin{array}{l}5.76 \\
<0.001 *\end{array}$ & $\begin{array}{l}23.95 \\
<0.001 *\end{array}$ & $\begin{array}{l}23.40 \\
<0.001 *\end{array}$ & $\begin{array}{l}17.5 \\
<0.001 *\end{array}$ & $\begin{array}{l}5.40 \\
<0.001 *\end{array}$ & $\begin{array}{l}15.31 \\
<0.001^{*}\end{array}$ \\
\hline Gr. II (n=6) & $2.3 \pm 1.03$ & $9.61 \pm 2.47$ & $135 \pm 12.87$ & $693 \pm 62.40$ & $116 \pm 9.76$ & $11.22 \pm 2.06$ & $24 \pm 5.26$ \\
\hline Gr. III $(n=6)$ & 4. $1 \pm 1.42$ & $13.26 \pm 2.76$ & $162 \pm 13.1$ & $835 \pm 73.20$ & $144 \pm 11.19$ & $9.20 \pm 2.00$ & $16 \pm 4.88$ \\
\hline $\begin{array}{l}\text { test } \\
\text { p }\end{array}$ & $\begin{array}{l}2.51 \\
0.03 *\end{array}$ & $\begin{array}{l}2.41 \\
0.036^{*}\end{array}$ & $\begin{array}{l}3.60 \\
0.005 *\end{array}$ & $\begin{array}{l}3.62 \\
0.004 *\end{array}$ & $\begin{array}{l}4.62 \\
0.001 *\end{array}$ & $\begin{array}{l}1.72 \\
0.11 \\
\end{array}$ & $\begin{array}{l}2.73 \\
0.021 *\end{array}$ \\
\hline
\end{tabular}

$* \mathrm{P}$ is considered statistically significant if $\leq 0.05$.

Table 4 Showing The Mean Area \% Of Caspase-3 Expression For Groups I, II And III In $2^{\text {nd }}$ Week Sections:

\begin{tabular}{|c|c|c|c|}
\hline Mean area $\%$ of caspase- 3 expression & Group I & Group II & Group III \\
\hline at 2 wks & 0.0 & 0.0 & 0.16 \\
\hline at $4 \mathrm{wks}$ & 0.0 & 0.07 & 0.34 \\
\hline at $6 \mathrm{wks}$ & 0.0 & 0.0 & 0.18 \\
\hline
\end{tabular}

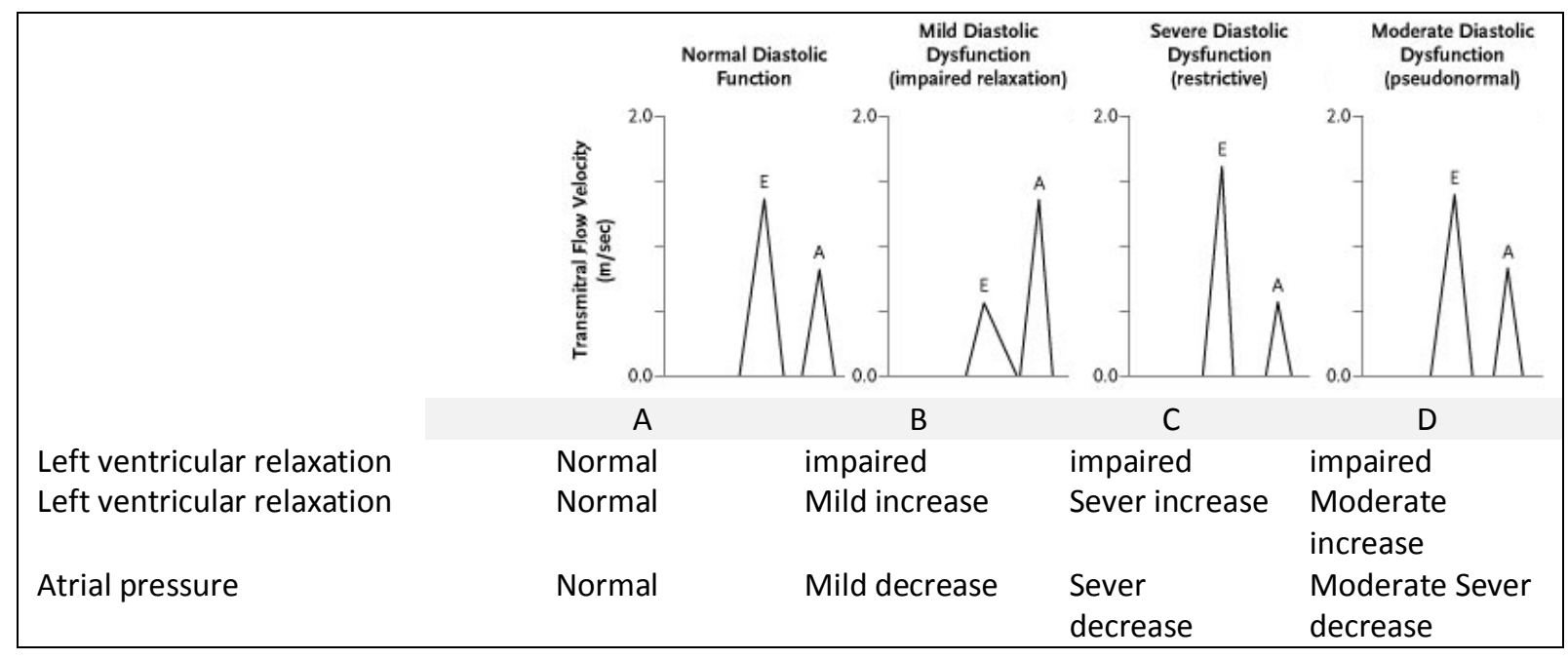


Fig. I ECG of rabbits treated with $\operatorname{Imb}$ in low dose (group II) showed the abnormal relaxation pattern (mild diastolic dysfunction) is brought by abnormally slow left ventricular relaxation, a reduced velocity of early filling (E wave), an increase in the velocity associated with atrial contraction (A wave), and a ratio of $E$ to A that is lower than normal. A (control group), B(after $2 \mathrm{wks}$ ), C (after $4 \mathrm{wks}$ ) and D (after $6 \mathrm{wks}$ ).

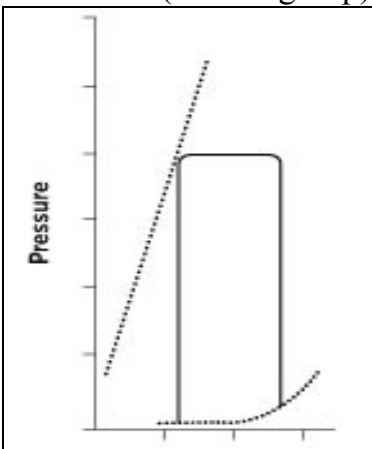

Left Ventricular Volume

A

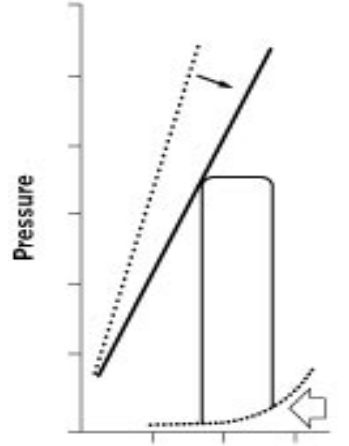

Left Ventricular Volume

B

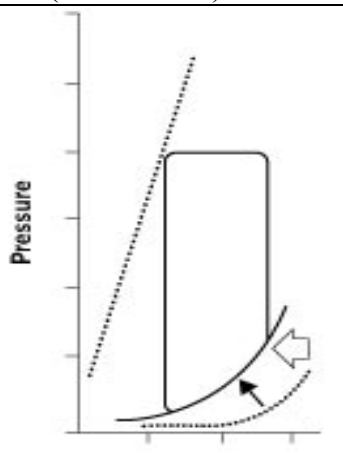

Left Ventricular Volume

C

LV normal LV systolic dysfunction LV diastolic dysfunction.

Fig. II ECG of rabbits treated with $\mathrm{Imb}$ in high dose (group III) after 4 wks showed left ventricular pressurevolume loops in systolic and diastolic dysfunction. A control group( LV normal), B( LV systolic dysfunction) and C( LV diastolic dysfunction).

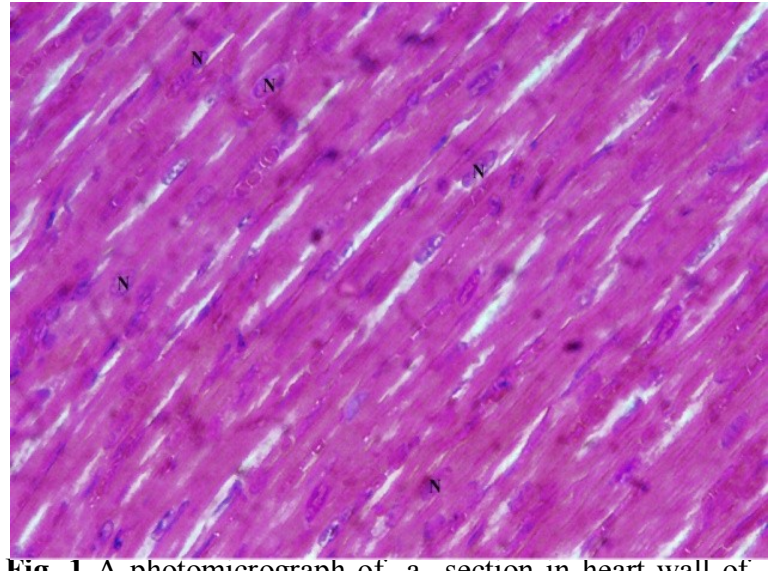

Fig. 1 A photomicrograph of a section in heart wall of control group (group I) showing myocardium formed of cardiac myocytes with oval centrally located nuclei ( [H\&E, X 400]

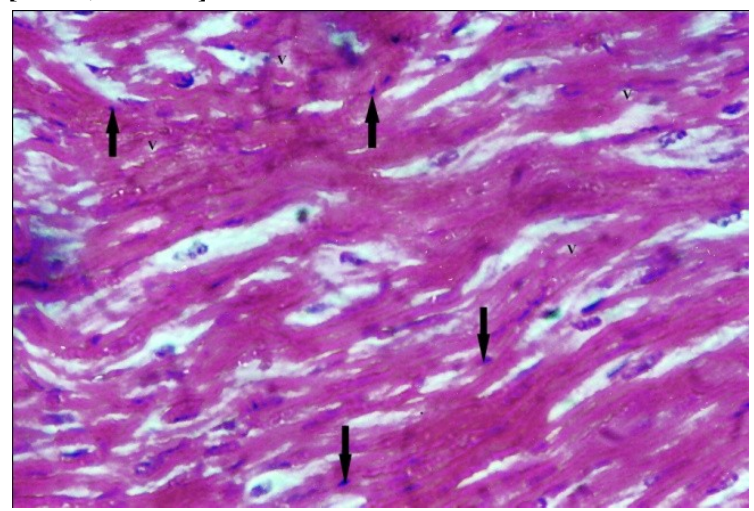

Fig. 3 A photomicrograph of a section in heart wall of high dose group (group III) 2nd weeks after intake showing moderate cytoplasmic vacuolization (V) and pyknosis of some cardiac myocytes (black arrow). [H\&E，X 400]

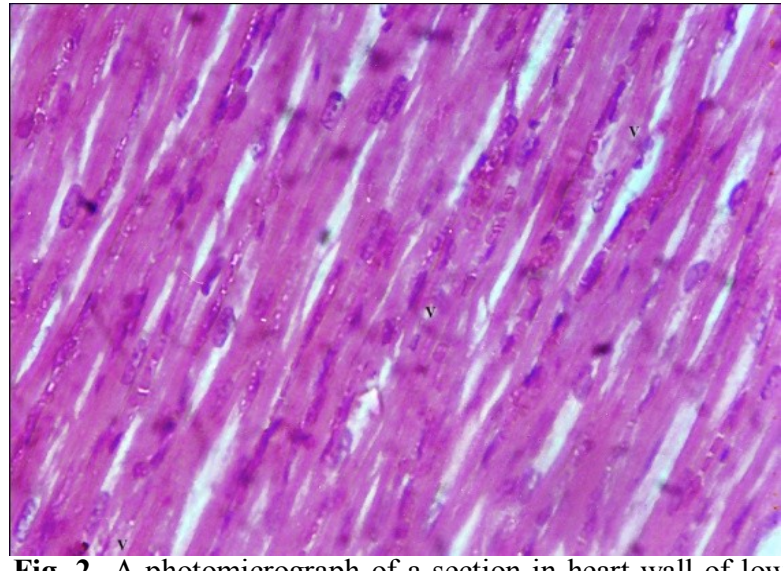

Fig. 2 A photomicrograph of a section in heart wall of low dose group (group II) $4^{\text {th }}$ weeks after $\operatorname{Imb}$ intake showing mild cytoplasmic vacuolization of a few cardiac myocytes (V). [H\&E, X 400]

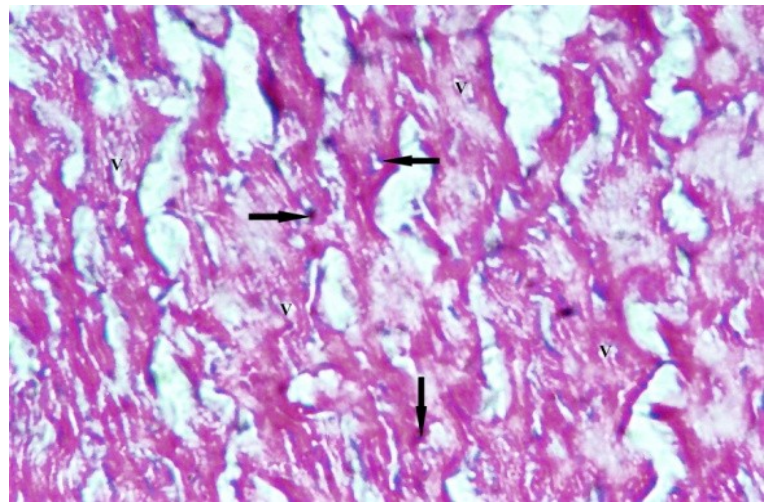

Fig. 4 A photomicrograph of a section in heart of high dose group (group III) 4 weeks after Imb intake showing sever cytoplasmic vacuolization (V), pyknosis of cardiac myocytes (black arrow) and widened intercellular space (IC). [H\&E, X 400] 


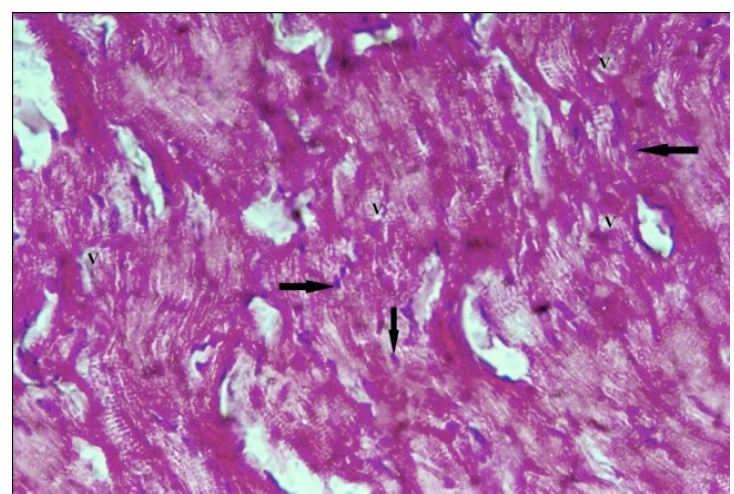

Fig. 5 A photomicrograph of a section in heart wall of high dose group (group III) 6 weeks after Imb intake (withdrawal sample) showing moderate cytoplasmic vacuolization (V) and pyknosis of some cardiac myocytes (black arrow). [H\&E, X 400]

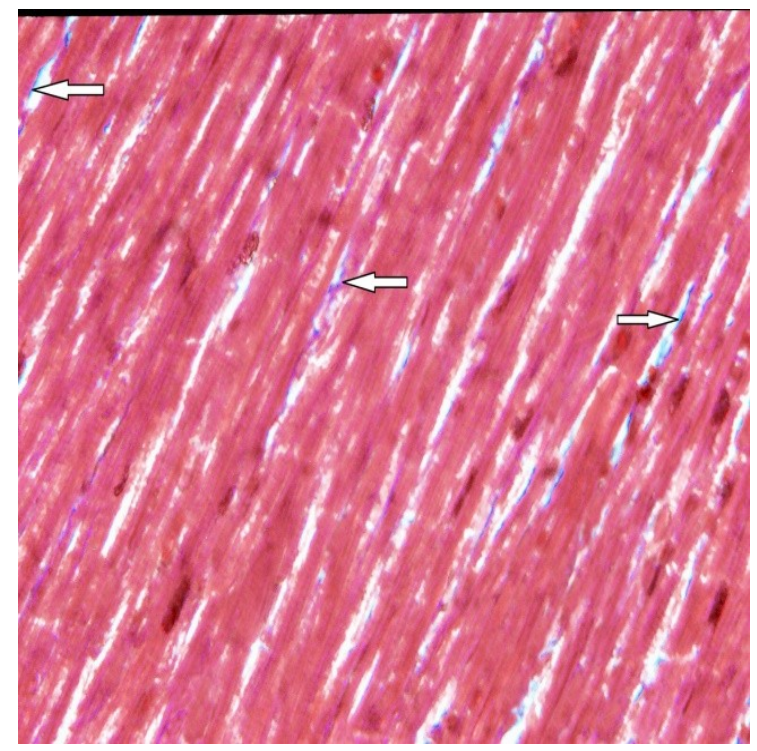

Fig. 6 A photomicrograph of a section in heart wall of control group (group I), showing minimal collagen fibers in between cardiac myocytes (white arrow). [Masson's trichrome, $X$ 400]

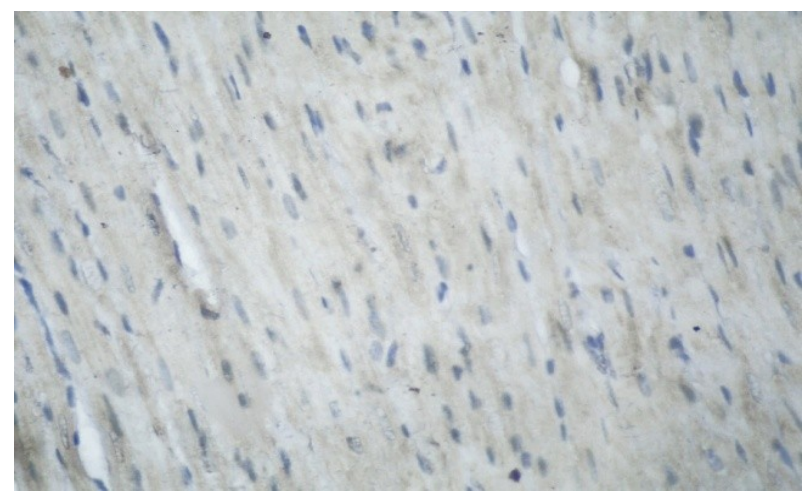

Fig. 8 A photomicrograph of a section in heart wall of control group (group I), showing negative caspase-3 immunostaining of cardiac myocytes [munohistochemical stain, X 400]

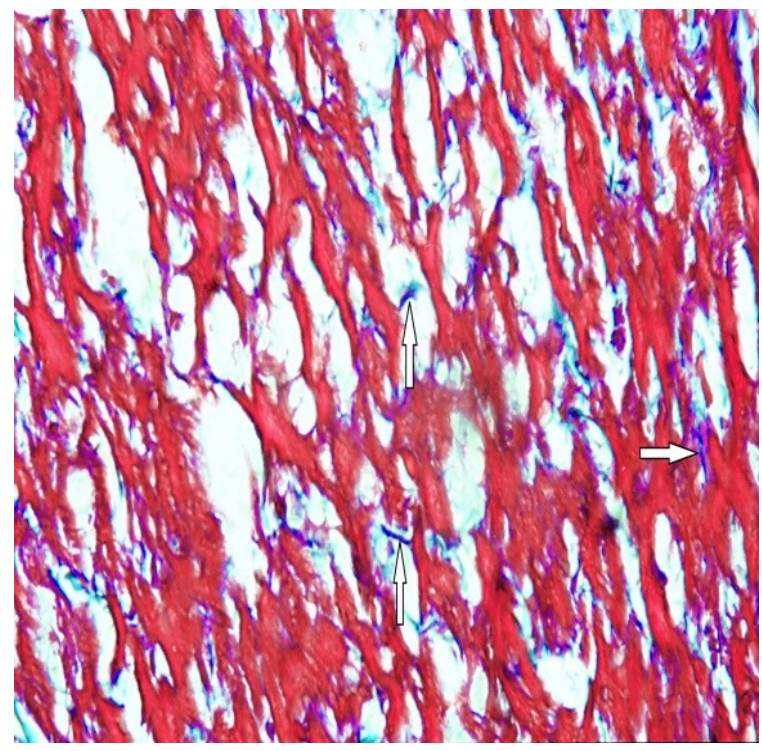

Fig. 7 A photomicrograph of a section in heart wall of high dose group (group III), 4 weeks after $I m b$ intake showing a few collagen fibers accumulation in between cardiac myocytes (white arrow).[Masson's trichrome, X 400]

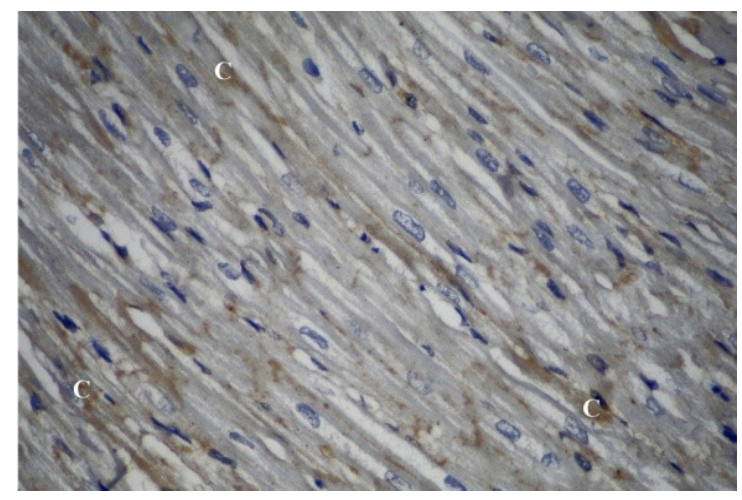

Fig. 9 A photomicrograph of a section in heart wall of low dose group (group II), 4 weeks after $\operatorname{Imb}$ intake showing mildly expressed caspase- 3 reaction in cardiac myocytes cytoplasm(C) [Immunohistochemical stain, $X$ 400] 


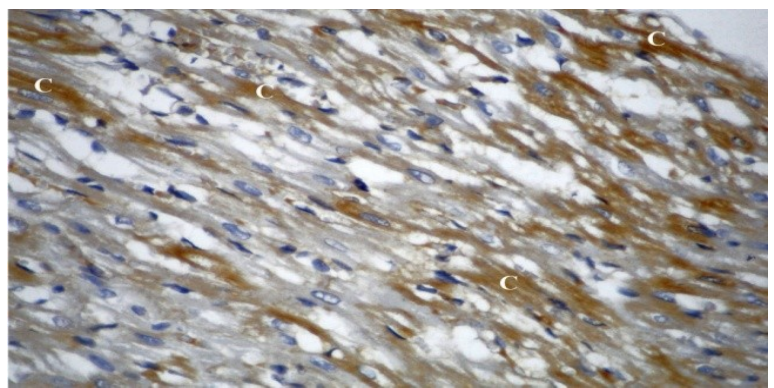

Fig. 10 A photomicrograph of a section in heart wall of high dose group (group III), 2 weeks after Imb intake showing moderately expressed caspase- 3 reaction in cardiac myocytes cytoplasm [Immunohistochemical stain, X 400]

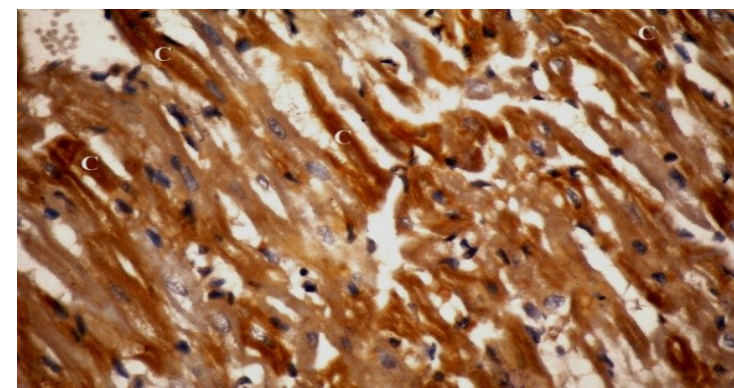

Fig. 11 A photomicrograph of a section in heart wall of high dose group (group III), 4 weeks after Imb intake showing highly expressed caspase-3 reaction in cardiac myocytes cytoplasm (C). [Immunohistochemical stain, $X$ 400]

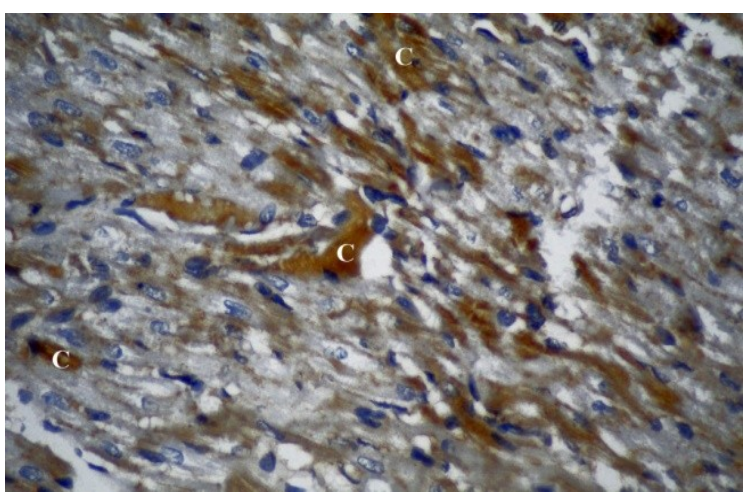

Fig. 12 A photomicrograph of a section in heart wall of high dose group (group III), 6 weeks after Imb intake (withdrawal sample) showing moderately expressed caspase-3 reaction in cardiac myocytes cytoplasm

(C). [Immunohistochemical stain, X 400]

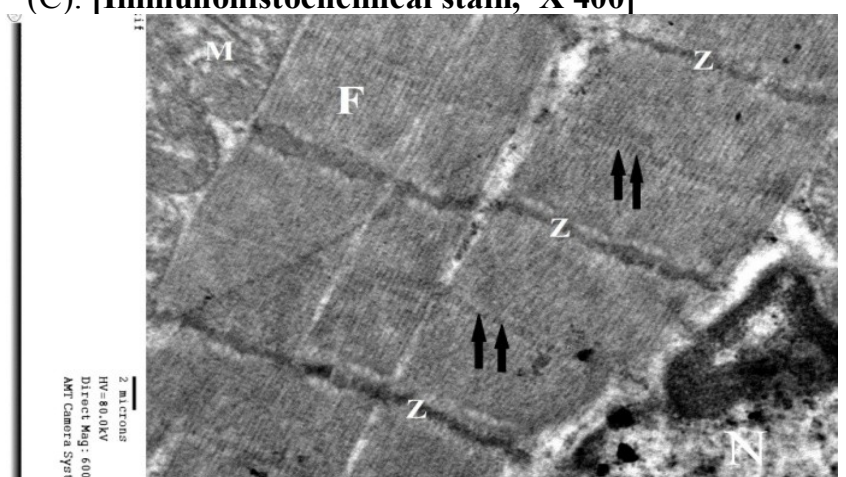

Fig. 13 An electron micrograph of a section in heart wall of control group (group I), showing well organized myofibrils (F), $Z$ discs ( $\mathrm{Z}$ ), $M$ lines (double black arrow), nucleus $(\mathrm{N})$ and mitochondria (M). [EM, X 6000]

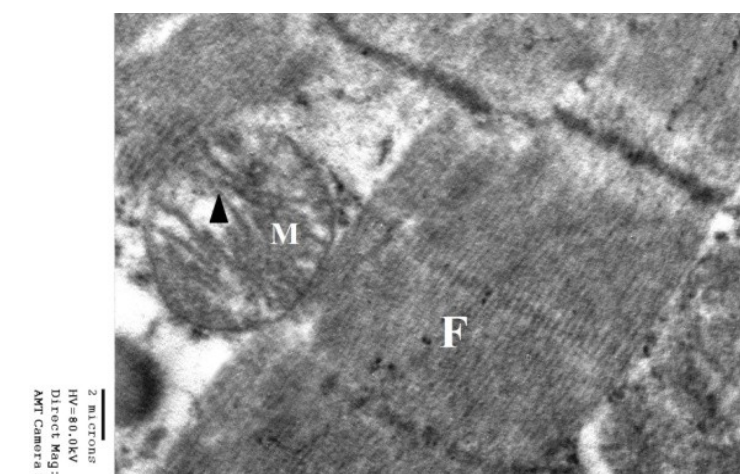

Fig. 14 An electron micrograph of a section in heart wall of control group (group I), showing well organized myofibrils (F) and normal spherical mitochondrial $(\mathrm{M})$ with intact mitochondrial crista (black arrow head).
[EM, X 10000] 


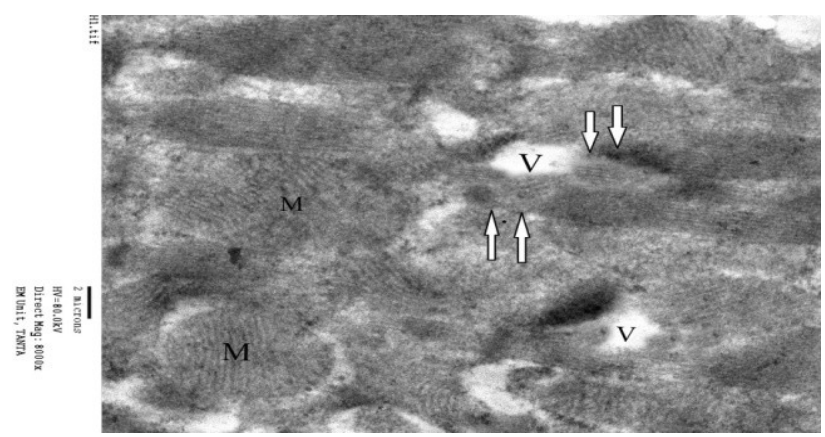

Fig. 15 An electron micrograph of a section in heart wall of low dose group (group II), 4 weeks after $I m b$ intake showing partial myofibrils disorganization (white double arrows), mild vacuolization (V) and slight mitochondrial swelling (M). [EM, X 8000]

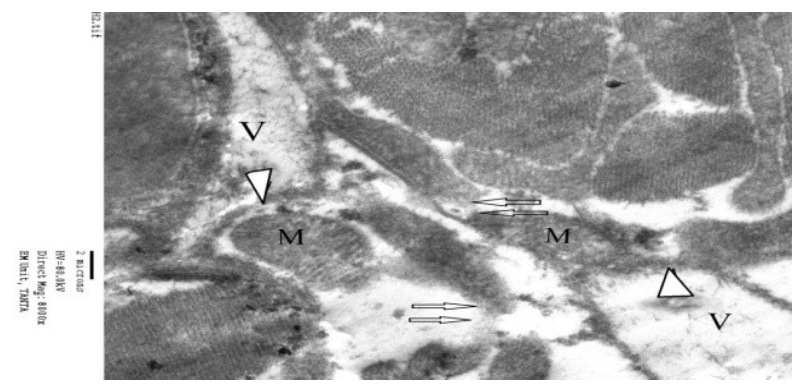

Fig. 17 An electron micrograph of a section in heart wall of high dose group (group III), 4 weeks after Imb intake showing extensive myofibrils disorganization (white double arrows), vacuolization (V), atrophic mitochondria with disruption of the crista (M) and portion of sarcoplasmic reticulum forming a membrane whorls immediately adjacent to mitochondria (white arrow head)

[EM, X 8000]

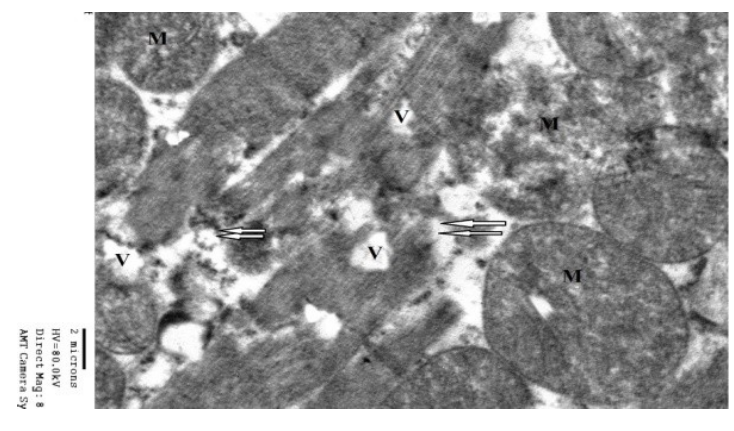

Fig. 16 An electron micrograph of a section in heart wall of high dose group (group III), 2 weeks after Imb intake showing partial myofibrils disorganization (white double arrows), moderate vacuolization (V) and mitochondrial swelling with disruption of the cristae (M). [EM, X 6000]

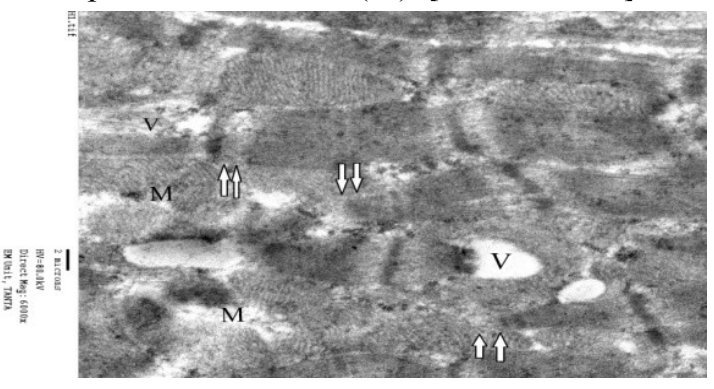

Fig. 18 An electron micrograph of a section in heart wall of high dose group (group III), 6 weeks after $I m b$ intake (withdrawal sample) showing partial myofibrils disorganization (white double arrows), moderate vacuolization (V) and mitochondrial swelling with disruption of the cristae (M).

[EM, X 6000]

\section{Discussion}

Imatinib (Imb) mesylate (Glivec, Gleevec), a small molecule tyrosine kinase inhibitor, is applied successfully as standard therapy for the treatment of chronic myeloid leukaemia (CML) and gastrointestinal stromal tumours (GIST) [25].

Cardiac toxicity is frequently the indication for discontinuation of chemotherapeutic treatment in patients with tumors that remain sensitive to chemotherapy. $\operatorname{Imb}$ is fully approved for the treatment of patients with CML in chronic phase after failure of interferon therapy in blast crisis and in accelerated phase [26]. This study was conducted to evaluate the cardiotoxicity of Imb in adult male rabbits.

In the present study electrocardiograph (ECG) of low dose of Imb treated rabbits (group II) showed mild diastolic dysfunction while group III (Imb in high dose), ECG showed left ventricular systolic and diastolic dysfunction. This results was agreed with Kerkela et al. [27]. It was reported that $I m b$-treated mice develop left ventricular contractile dysfunction and cellular abnormalities suggestive of toxic myopathy.

In accordance with these results, Saad et al [28] found that mice treated with $\operatorname{Imb}$ for 3 to 6 wk developed left ventricular contractile dysfunction and ultrastructural myocyte alterations. These investigators suggested that the pathogenic mechanism of $\operatorname{Imb}$ related toxicity may involve interfering with one or more of the antitumor targets (Abelson proto-oncogene) also present in the heart.

Additionally, these results are similar to those reported by Breccia et al., [7] who reported cardiac parameters evaluation before, during and after $\operatorname{Imb}$ treatment (high dose of $800 \mathrm{mg} /$ day) will be helpful in providing clear evidence on the possible role of $\operatorname{Imb}$ as a cardiotoxic drug.

Interestingly, a later post approval research study in mice reported adverse cardiovascular changes in response to Imb, including LV dysfunction. In accordance, Kerkela et al. [27] reported 10 cases where patients receiving Imb developed significant LV dysfunction. It is important to note that in this study, the total number of patients reviewed by the authors in identifying these cases was unclear. However, affected individuals had a 
normal LV ejection fraction (LVEF) (56 $\pm 7 \%$ ) prior to therapy but presented with HF after an average of $7.2 \pm$ 5.4 months of treatment. HF was associated with mild LV dilation, and the mean LVEF declined to $26 \pm 8 \%$ [26]. The majority of the affected patients in the Kerkela [27] reported that comorbidities are including hypertension, Coronary artery disease (CAD), or diabetes [29].

On the other hand, Atallah et al. [30], Force et al. [31] reported that $I m b$ has a cardio protective effect possibly mediated through inhibition of platelet-derived growth factor receptor (PDGFR) both in animals and in cell cultures.

In addition, Wolf et al. [32] found that cardiac alterations (necrosis) in rats occurred only at high nonclinically relevant doses. A dose-dependent, short-lasting decrease in arterial blood pressure (BP) was observed immediately after single dose administration in rats but no electrocardiogram (ECG) changes were observed.

However, other studies found a low clinical incidence of cardiotoxic symptoms [30], [33],[34]. These relatively negative studies were denying the existence of significant cardiotoxicity related to Imb, were considered insufficient to assure that adverse cardiac effects are not a major issue in this therapy. Authors explained these negative studies by the main methods used in these studies, history, physical examination and ECG, are considered insensitive for recognizing heart failure, and cannot detect asymptomatic left ventricular (LV) dysfunction, which has important prognostic and therapeutic meaning As a result, part of the discrepancy in the occurrence of cardiotoxicity may be related to limitations of the diagnostic methods used to evaluate cardiovascular function in Imb-treated patients [35],[36].

As regards biochemichal parameters this work revealed that $(\operatorname{Imb})$ treatment produced significant increases in serum CK-MB, GPx, LDH and AST activity compared with control group. Moreover, (Imb)-treated rabbits showed significant reductions in the cardiac GPx activity and total NOx concentration, as well as elevations in cardiac Tnc $\mathrm{T}$ and cardiac MDA production. These results are in accordance with those reported by Yeh and Bickford [37].

In accordance with these results, Jaiswal [38] reported cardiotoxic effect of (Imb) through inhibition of (ABL) leading to activation of the endoplasmic reticulum stress response, collapse of the mitochondrial membrane, release of cytochrome $\mathrm{C}$ into the cytosol, reduction in cellular ATP content and cell death. Inhibition of c-Ab1 in the cardiac myocytes by (Imb) treatment might contribute to attenuation of cardiac GPx activity. Reduction of GPx activity due to (Imb) treatment was associated with significant increase in cardiac GSH content [36]. Moreover, treatment of rabbits with $(\operatorname{Imb})$ resulted in significant increase in cardiac MDA production level due to Imatinib- induced myocardial C-Ab1 and PDGF receptor inhibition, contributing to peroxidative-induced myocardial damage agree with these results Jaiswal [38]; Li et al [39] and Nilsson et al [40].

Additionally, agree with these results, Sato et al. [14] reported that the rise of cTnT before starting Imb and the evaluation of cTnT soon after Imb have accurately predicted the development of acute left ventricular (LV) depression.

The measurement of serum cardiac troponins (cTnI and cTnT) are the gold standard for diagnosis of acute myocardial events in man and have gained increasing recognition as a new tool for the assessment of cardiotoxicity in safety studies [14].Also, Wolf et al. [32] also reported that levels of cTnI increased in some Imb-treated rats. In this instance, increases in heart rate and contractility preceded necrotic degeneration of the myocytes.

Disagree with these results Perik et al., [41] found that, plasma N-terminal pro-brain natriuretic peptide (NT-proBNP) and serum cTnT levels did not change during Imb treatment, further indicating that treatment with $\operatorname{Imb}$ is not related to an increased incidence of subclinical cardiotoxicity. Standard cardiac monitoring does not appear required with this agent.

A cross talk between cardiac myocytes and nonmyocytes via humoral factors plays an important role in the development of cardiac growth. Exploration of the protective effect of humoral factors produced from nonmyocytes against acute myocardial injury might lead to mechanistic insights. Thus, inhibition of PDGF receptors by Imb might contribute to inhibition of neovascularization and collaterals formation leading to hypoxia and oxidative [39],[40].

As regards histopathological changes, in the present study, cardiac toxicity was evident in high dose of Imb (marked cytoplasmic vacuolization, pyknosis and highly expressed caspase-3 of myocytes) that became moderate 2 weeks after the stoppage of the drug indicating the reversibility of the effect and this agreed with Schelling et al. [8] who reported that a loss of cardiac function occurred only at the higher doses of Imb where Imb $800 \mathrm{mg}$ daily, versus $400 \mathrm{mg}$ daily, is a more toxic but not more effective dose [42],[43]. Wolf et al. [32] have also reported myocyte necrosis in rats treated with higher doses of Imb for $28 \mathrm{~d}(120 \mathrm{or} 200 \mathrm{mg} / \mathrm{kg})$.

In the present study, immunohistochemical analysis of hearts from rabbits treated with $\operatorname{Imb}$ revealed to increase areas of reactivity were mainly in the cytoplasm of myocytes undergoing necrosis. Kerkela et al. [27] found that the formation of powerful oxidants, such as peroxynitrite, could be a factor in the pathogenesis of 
Imb-induced myocyte necrosis induce apoptotic myocyte death in vivo and also corroborate that of a report in which exposing isolated cardiac myocytes to $\operatorname{Imb}$ induced several markers of apoptosis.

In spite of cardiac toxicity that evident in high dose Imb group of the present study, Masson's trichrome staining showed minimal increase of collagen fibers accumulation between cardiac myocytes compared with control group and this agreed with Kerekl et al.[27] who reported that Masson's trichrome staining showed no significant fibrosis in between cardiac myocytes in Imb treated mouse. This can be explained by wang et al.[44] and Rosenbloom et al., [45] which reported that the transforming growth factor- $\beta$ (TGF- $\beta$ ) is the single most important cytokine promoting fibrogenesis and the major mechanism underlying the beneficial actions of $(\mathrm{Imb})$ is the inhibition of TGF- $\beta$. Stimulated tyrosine kinase cellular Abelson (C-Abl) and the ensuing reduction in fibroblast proliferation and diminishing the fibrogenic effects of TGF- $\beta$.

In high dose of Imb group of the present study, electron microscope study showed partial myofibrils disorganization, minimal vacuolization and mitochondrial swelling with disruption of the cristae in the $2^{\text {nd }}$ week sections that became extensive with mitochondrial destruction and vacuolar degeneration of portion of sarcoplasmic reticulum forming a membrane whorls in the $4^{\text {th }}$ week sections. These resulrs agree with Strebhardt and Ullrich [46] who reported that transmission electron micrographs of samples from the individuals hearts on Imb showed numerous membrane whorls in the sarcoplasmic reticulum, and in or immediately adjacent to mitochondria that showed abnormalities and these abnormalities are dose-dependent.

In the present studies, Imb -induced mitochondrial alterations were not detected by light microscopy but were detected by electron microscopy. In accordance with these results Kerkela et al [27]and Chu et al [47]. Alterations in mitochondrial structure were found by transmission electron microscopy in human cardiac biopsy samples [27], [48]. Furthermore, exposure of rat myocytes to Imb was found to cause changes in the mitochondrial membrane potential and cell viability [48].

The cardiotoxic actions of Imb are thought to be mediated through suppression of fusion protein BCRABL activity, one of its tyrosine kinase targets [31]. The myocyte mitochondria have often been mentioned as a cellular site that is adversely affected by exposure to TKI. In mice, both Imb inhibits kinase pathways and induces changes in mitochondrial morphology sufficient to open the mitochondrial permeability transition pore. TKIs also initiate events up stream of the mitochondria, which result in activation of the cardiac endoplasmic reticulum stress response.

Other opinion that cardiotoxicity could not be observed in a middle-size sample under long-term therapy with $\operatorname{Imb}$ and there were evidence of absence of significant cardiotoxicity related to Imb [49]. Rosenbloom et al. [45] reported that randomizing a daily dose of $400 \mathrm{mg}$ vs. $800 \mathrm{mg}$, they could not identify an excess of cardiac events in the study population so they could not confirm previous suggestions of Imatinibinduced cardiac toxicity and there does not seem to be any relation to dose.

The mechanisms of Imb cardiotoxicity explained by Mauro and Deininger [50] who reported that tyrosine kinase cellular Abelson $\mathrm{C}-\mathrm{Ab} 1$ has been implicated in cell response to DNA damage and oxidative stress. Imb- induced inhibition of $\mathrm{C}-\mathrm{Ab} 1$ might contribute to endogenous antioxidant depletion thus, $\mathrm{C}-\mathrm{Ab} 1$ might be important in the control of cellular antioxidant defense mechanisms. Imb mesylate-induced cardiac toxicity is also facilitated by several relevant co-morbidities such as previous cardiovascular disease or renal failure [51].

In addition, Gupta et al[52] explained Imb Cardiotoxity mechanisms by Imb induces oxidative stress via ROS generation, depletion of cellular endogenous antioxidant reserve, release of cytochrome $\mathrm{C}$ and apoptosis-inducing factor (AIF) from the mitochondria, activation of caspases, leading to cellular apoptosis. Moreover it might be speculated that Imb was exacerbating myocardial oxidative stress and reduced total NOx concentration in the cardiac tissue due to inhibition of PDGF, as well as cellular Akt that might be of great importance in the activation of endothelial nitric oxide synthase (eNOS). Takahashi and Mendelson [53], explaining the imatinib-induced total NOx content depletion.

\section{Conclusion}

This study concluded that $\operatorname{Imb}$ exerts irrevesible cardiotoxic effects that are manifest through a complex pattern of cellular, biochemical and ECG alterations, the severity of $\operatorname{Imb}$ cardiotoxicity can be influenced by increase dose and period of $\operatorname{Imb}$ administration.

\section{References}

[1] R Hehlmann, A. Hochhaus and M. Baccarani, Chronic myeloid leukemia, Lancet, 370, 2007, 342-350.

[2] M A Siddiqui and L.J. Scott, Imatinib: a review of its use in the management of gastrointestinal stromal tumors. Drugs, 67(5), 2007, 805-820.

[3] M Talpaz, N. P. Shah, H. Kantarjian, et al, "Dasatinib in imatinib-resistant Philadelphia chromosome-positive leukemias". N. Engl. J. Med. 354 (24): (2006), 2531-41.

[4] K Cwynarski, R. Laylor, E. Macchiarulo et al, Imatinib inhibits the activation and proliferation of normal T lymphocytes in vitro. Leukemia; 18, 2004, 1332- 1339. 
[5] D J DeAngelo and J. Ritz, Imatinib Therapy for Patients with Chronic Myelogenous Leukemia: Are Patients Living Longer? , Clinical Cancer Research, 10, 2008, 1-3.

[6] B J Druker, F. Guilhot, S G O'Brien, I Gathmann, et al, Five years follow-up of patients receiving Imatinib for chronic myeloid leukemia. N. E. J. M.,355, 2010, 2408-2420.

[7] M Breccia, F. Gentilini, L. Cannella, et al, Ocular side effects in chronic myeloid leukemia patients treated with Imatinib. Leukemia, Research, 32, 2008,1022-1025.

[8] $\mathrm{m}$ w Schellings, B. Lowenberg, and Y. M. Pinto, Another Look at Imatinib Mesylate. N. E. J. M, 2007, $356: 11$.

[9] K Seiter, Update of recent studies in chronic myeloid leukemia, Journal of Hematology and Oncology; 2 (Suppl 1), (2009), A2.

[10] G E Paget and J. M. Barnes, Toxicity test for evaluation of drug activities, in D R Laurence and A. L. Bacharach (Eds), Pharmacometrics, 1 (London and New York Academic Press, (1964) P 135.

[11] R M Lang, M. Bierig, R. B. Devereux, F. A. Flachskampf, et al., Recommendations for chamber quantification: a report from the American Society of Echocardiography's Guidelines and Standards Committee and the Chamber Quantification Writing Group, developed in conjunction with the European Association of Echocardiography, a branch of the European Society of Cardiology, $J$ Am Soc Echocardiogr;18(12), (2005)1440-1463.

[12] W L Miller, R. S. Wright, C. G. McGregor, et al., Troponin levels in patients with amyloid cardiomyopathy undergoing cardiac transplantation, Am J Cardiol., 88, (2001) 813-815.

[13] A Dispenzieri, R. A. Kyle, M. A. Gertz et al, Survival in patients with primary systemic amyloidosis and raised serum cardiac troponins, Lancet, 361,(2003),1787-1789.

[14] Y Sato, T. Yamada, R. Taniguchi, et al., Persistently increased serum concentrations of cardiac Troponin T in patients with idiopathic dilated cardiomyopathy are predictive of adverse outcomes, Circulation, 103,(2001)369-379.

[15] J Mair, D. Morandell, N. Genser, et al. Equivalent early sensitivities of myoglobin, creatine kinase- MB mass, creatine kinase isoforms ratios, and cardiac troponins I and T for acute myocardial infaraction.Clin Chem. 1995;41:1266-1272.

[16] A Remppis, T. Scheffaid, O. Karrer et al. Assessment of reperfusion of the infarct zone after acute myocardial infarction by serial cardiac Troponin T measurement in serum. Br Heart J $1994 ; 71: 3$ : 242-6.

[17] Mohur A, Cook IJY. Simple methods for measuring serum levels of glutamic-oxalo acetic and glutamic-pyruvic transaminase in routine laboratories. J Clin Pathol. 1957;10:394-399.

[18] Valenzuela A. The biological significance of malondialdehvde determination in the assessment of tissue oxidative stiess. Life Sci., 1991:48:301-309.

[19] D E Paglia and W. N. Valentine, Studies on the quantitative and qualitative characterization of erythrocyte glutathione peroxidase. J. Lab. Clin. Med. 70, (1967), 158-169.

[20] K M Miranda, M. G. Espey, D. A. Wink, A rapid simple spectrophotometric method for simultaneous detection of nitrate and nitrite. Nitric Oxide, 5, (2001), 62-71

[21] M Gamble, The Hematoxylin and eosin, in A D Bancroft and M. Gamble (Eds.) Theory \& Practice of histological techniques, 6(Livingstone of El Sevier, Philadelphia, Churchill, 2008),Ch. 9, PP. 121 - 134.

[22] M L Jones, A. D. Bancroft and M. Gamble, Connective tissue and stains, in Bancroft, AD and M. Gamble, (Eds.) Theory \& Practice of histological techniques, (Churchill Livingstone of El Sevier, Philadelphia. 2008), Ch.10. PP. 135 - 161.

[23] M A Hayat, Principles and Chemical fixation, in Principles and Techniques of Electron Microscopy: Biological Applications, 4,(Cambridge University Press; UK, 2000), Chapter 2.PP. 4-85.

[24] J H Zar, Biostatistical Analysis, 4, (Prentice Hall, Upper Saddle River, NJ. ,1999) PP. 662, plus appendices

[25] M Nakajima, and W. Toga, Tyrosine kinase inhibitor as a therapeutic drug for chronic myelogenous leukemia and gastrointestinal tumor. Nippon Yakurigaku Zasshi, 122, (2003),482-490.

[26] M H Cohen, J. R. Johnson, R. Pazdur, U.S. Food and Drug Administration drug approval summary: conversion of imatinib mesylate (STI571; Gleevec) tablets from accelerated approval to full approval, Clin Cancer Res,11,(2005),12-19.

[27] R Kerkel, L. Grazette, R. Yacobi, C. Iliescu, et al., Cardiotoxicity of the cancer therapeutic agent Imatinib mesylate, Nature Medicine; 12, (2006), 908-916.

[28] S Y Saad, K. M. Alkharty, and M. M. Arafah, Cardiotoxic effects of arsenic trioxide/imatinib mesilate combination in rats, $J$ Pharm Pharmacol 58, (2006), 567-73.

[29] A Hatfield, S. Owen and P. R. Pilot, In reply to "Cardiotoxicity of the cancer therapeutic agent imatinib mesylate" [letter]. Nat Med,(2007),13:13.

[30] E Atallah, J. Durand, H. Kantarjian and J. Cortes, Congestive heart failure is a rare event in patients receiving Imatinib therapy, Blood, 110 (4)(2007), 1233-1237.

[31] T Force, D. S. Krause and R. A. Van Etten, Molecular mechanisms of cardiotoxicity of tyrosine kinase inhibition, Nat. Rev. Cancer; 7 (5)(2007), 332- 344

[32] A Wolf, P. Couttet, M. Dong, O. Grenet, et al., Imitanib does not induce cardiotoxicity at clinically relevant concentrations in preclinical studies. Leuk Res 34, (2010), 1180-88.

[33] J Verweij, P. G. Casali, D. Kotasek, A. L. Cesne, P. Reichard, et al., Imatinib does not induce cardiac left ventricular failure in gastrointestinal stromal tumours patients, Eur. J. Cancer; 43(2007),974-978.

[34] P J Perik, B. Rikhof, F. A. de Jong, et al., Results of plasma N-terminal pro B-type natriuretic peptide and cardiac troponin monitoring in GIST patients do not support the existence of Imatinib-induced cardiotoxicity. Annals of Oncology; 19(2), (2007)359-361.

[35] J C Trent, S. S. Patel, J. Zhang, et al., Rare incidence of congestive heart failure in gastrointestinal stromal tumor and other sarcoma patients receiving imatinib mesylate. Cancer, 116, (2010)184-92.

[36] Z R Estabragh, K. Knight, S. J. et al., A prospective evaluation of cardiac function in patients with chronic myeloid leukaemia treated with imatinib. Leuk Res 35, (2011),49-51.

[37] E T H Yeh and C. L. Bickford, Cardiovascular Complications of Cancer Therapy. J. Am Coll. Cardiol, 53, (2009), 2231- 2247.

[38] A K Jaiswal, Nrf2 signaling in coordinated activation of antioxidant gene expression.FreeRadic. Biol.Med.36: (2004),1199-1207.

[39] B Li, X. Wang, N. Rasheed, et al., Distinct roles of c-Ab1 and Atm in oxidative stress response are mediated by protein kinase C delta. Genes Dev. 18: (2004), 1824-1837

[40] I Nilsson, M. Shibuya, and S. Wennstrom, Differential activation of vascular genes by hypoxia in primary endothelial cells. Exp. Cell Res. 299(2004),476-485.

[41] P J Perik, B. Rikhof, F. A. de Jong, F. A. et al., Results of plasma N-terminal pro B-type natriuretic peptide and cardiac troponin monitoring in GIST patients do not support the existence of imatinib-induced cardiotoxicity, Ann Oncol 19, (2008), $359-61$.

[42] M E Williams, Imatinib Dosing for Patients with Chronic-Phase CML, Hematology and Oncology Journal Watch; 5(3) (2009),19.

[43] J H W Distler, and O. Distler, Imatinib as a novel therapeutic approach for fibrotic disorders. Rheumatology; 48 (1) (2008)2-4. 
[44] S Wang, M. C. Wilkes, E. B. Leof and R. Hirschberg, Imatinib mesylate blocks a non-Smad TGF- $\beta$ pathway and reduces renal fibrogenesis in vivo. F.A.S.E.B. J.; 19 (2009), 1-11.

[45] J Rosenbloom, S. V. Castro and S. A. Jimenez, Narrative Review: Fibrotic Diseases: Cellular and Molecular Mechanisms and Novel Therapies. Ann. Intern. Med.; 152(3) (2010), 159-166.

[46] K Strebhardt and A. Ullrich, Another Look at Imatinib Mesylate. N. E. J. M., 355: (2006), 2481- 2482.

[47] T F Chu, M. A. Rupnick, R. Kerkela, R., Cardiotoxicity associated with the tyrosine kinase inhibitor sunitinib, Lancet 370 , (2007),2011-2019.

[48] W J Freebern, H. S. Fang, M. D. Slade, et al., In vitro cardiotoxicity potential comparative assessments of chronic myelogenous leukemia tyrosine kinase inhibitor therapies: dasatinib, imatinib and nilotinib, Blood ,110, (2007), 4582.

[49] A L Ribeiro, M. S. Marcolino, H. N. S. Bittencourt, et al., An evaluation of the cardiotoxicity of Imatinib mesylate. Leukemia Research; 32, (2008), 1809-1814.

[50] M J Mauro and M. W. Deininger, Management of Drug Toxicities in Chronic Myeloid Leukaemia, Best Practice \& Research Clinical Haematology; 22, (2009), 409-429.

[51] G Turrisi, F. Montagnani, C. Marinozzi, L. Bolognese and g. Fiorentini, Congestive heart failure during imatinib mesylate treatment. Int J Cardiol,(2009),123-8

[52] S Gupta, L. Yel, D. Kim, C. Kim, S. Chiplunkar and S. Gollapudi, Arsenic trioxide induces apoptosis in peripheral blood T lymphocyte subsets by inducing oxidative stress: a role of Bcl-2, Mol. Cancer Ther, 2(2003), 711-719

[53] S Takahashi and M. E. Mendelsohn, Synergistic activation of endothelial nitric oxide synthase (eNOS) by HSP90 and AKT: calcium-independent eNOS activation involves formation of an HSP90-Akt-CaM-bound eNOS complex, J. Biol. Chem., 278(2003), 30821-30827. 